\title{
The self-reference effect on memory in early childhood
}

Sheila J. Cunningham, Joanne L. Brebner, Francis Quinn and David J. Turk

This is the accepted version of the following article:

Cunningham, S.J., et al. 2014. The self-reference effect on memory in early childhood. Child Development. 85(2): pp.808-823.

which has been published in final form at http://dx.doi.org/10.1111/ cdev.12144. In addition, authors may also transmit, print and share copies with colleagues, provided that there is no systematic distribution of the submitted version, e.g. posting on a listserve, network or automated delivery. 


\section{RUNNING HEAD: THE SELF-REFERENCE EFFECT IN EARLY CHILDHOOD}

The self-reference effect on memory in early childhood

Sheila J. Cunningham ${ }^{1,2}$, Joanne L. Brebner ${ }^{2}$, Francis Quinn ${ }^{2,3}$, and David J. Turk ${ }^{2,4}$

1. Division of Psychology, University of Abertay Dundee, Bell Street, Dundee, UK, DD1 1HG

2. School of Psychology, University of Aberdeen, King's College, Aberdeen, UK, AB24 $2 U B$

3. School of Applied Social Sciences, Robert Gordon University, Aberdeen, UK, AB10 1FR

4. School of Experimental Psychology, University of Bristol, Priory Road, Bristol, UK, BS8 $1 T U$

Corresponding author: Sheila J. Cunningham

Contact details: Division of Psychology, University of Abertay Dundee, Bell Street, Dundee, UK, DD1 1HG.

Email: s.cunningham@abertay.ac.uk;

Tel: +44 (0)1382 308592

Fax: $+44(0) 1382308749$

\section{Author Note}

This research was supported by a grant from the European Research Council (202893) awarded to David J. Turk. We thank the children, parents, and teachers for their support of the research, and the four anonymous reviewers for their helpful comments. Data from Experiment 1 were presented at the 2011 SRCD annual meeting (Montreal, Canada). 


\section{THE SELF-REFERENCE EFFECT ON MEMORY IN EARLY CHILDHOOD}

Children develop a cohesive sense of self at a young age, and this is an influential and socially important construct by early childhood (Lewis, 2003; Fasig, 2000; Ross, Anderson, \& Campbell, 2011). Despite the importance of the self at this stage, its influence on cognition has received surprisingly little empirical attention. In the adult literature, a large body of research demonstrates that the self has a significant guiding role on cognition. For example, incoming information that is relevant to self receives more attention than non-self-relevant stimuli and elicits affective responses, and such information is subsequently more likely to be successfully retrieved from memory (e.g., Bargh, 1982; Conway \& Dewhurst, 1995a; Klein \& Loftus, 1988; Rogers, Kuiper, \& Kirker, 1977; Symons \& Johnson, 1997; Turk, Cunningham, \& Macrae, 2008; Turk, van Bussel, Waiter, \& Macrae, 2011). Specific selfsystems in the brain have been identified that are activated during self-processing, and these are argued to result from evolutionary advantages accrued by attending to and storing carefully information that is potentially relevant or useful to self (see Klein, 2012). There are considerable practical ramifications of self-referencing, such as false confidence in personal recollections, and memory strategies in education and old age. In short, understanding the influence of the self is critical to any full account of cognition.

Given the fundamental importance of self-referential processing systems, it is clearly of value of psychologists to apply a lifespan approach to understanding the functionality of the self (see Glisky, \& Marquine, 2009). However, the developing influence of the self on children's cognition is currently poorly understood. The developmental gap in the literature is very stark - despite the range of research showing how the self influences cognition in adults, little is known about how it operates in children. A great deal of research has examined how the self concept develops in infancy and toddlerhood, but almost none has investigated how 
this impacts on early cognition. The current inquiry seeks to address this deficit, exploring the influence of self-referencing on cognition in early childhood.

\section{The Self in Childhood}

There is a considerable body of research charting the stages through which a sense of self initially develops. Over the first year, infants are argued to develop an 'objective self' understanding, a concept that self is a unique entity that exists across time (Lewis, 2003). By 18 months, toddlers can show signs of self-awareness such as mirror recognition and the use of self-referent linguistic terms (see Lewis \& Ramsey, 2004). By 3 years, self-conscious emotions such as embarrassment and shame provide evidence of a 'subjective' sense of self (Lewis, 2003). Further, the sense of personal ownership is strong and socially important at this stage, suggesting that young children can process external items in a self-referent context (Ross et al., 2011).

The adult literature exploring the effects of the self on cognition have focused on the 'Self-Reference Effect' (SRE) on memory, the tendency for information encoded in a selfrelevant context to be afforded a memory advantage over information encoded semantically or with reference to other people (Rogers et al., 1997; Symons \& Johnston, 1997). A reliable SRE emerges with the standard encoding paradigm (for review see Symons \& Johnson, 1997), in which traits are evaluated with reference to self (e.g., “Are you modest?”), a nonintimate other-referent (e.g., "Is Barack Obama tidy?"), or in terms of their semantic or physical features (e.g., “Is 'calm' a positive word?”). A trait recognition or recall test is then used to assess whether encoding the items with reference to self elicits a memory advantage.

The SRE is particularly robust because it takes advantage of the multiple routes through which the self can influence cognition. For example, the autobiographical knowledge that accumulates in long-term memory provides a rich and accessible framework through which incoming self-relevant information can be organised and enriched (Klein \& Kihlstrom, 1986; 
Klein \& Loftus, 1988; Symons \& Johnson, 1997). Further, cues of self-relevance capture both executive and perceptual attention and increase levels of affective arousal (Bargh, 1982; Gray, Ambady, Lowenthal, \& Deldin, 2004; Turk, van Bussel, Brebner, Toma, Krigolson, \& Handy, 2011; Turk, van Bussel, Waiter et al., 2011). These systems combine to increase elaborative encoding, leading to episodic representations that are more likely to be retrieved than memories not encoded with reference to self (see Conway \& Dewhurst, 1995a; Van den Bos, Cunningham, \& Turk, 2010).

The SRE trait evaluation paradigm has been applied in a small number of development studies, with children who are sufficiently mature to meet the abstract task requirements. Mixed findings have emerged from this research. It has been suggested that the SRE increases between seven and ten years, in line with accumulating self-knowledge (Halpin, Puff, Mason, \& Marston, 1984; Ray, Shelton, Hollon, Michel, Frankel, Gross, \& Gabrieli, 2009). However, other studies suggest that a stable SRE can be demonstrated from an earlier age (from five years - Bennett \& Sani, 2008; from seven years - Pullyblank, Bisanz, Scott, \& Champion, 1985). The picture emerging from this limited number of studies is therefore unclear.

Adding to this research based on the standard SRE task, a small number of studies have used concrete, pictorial encoding tasks, which indicate an earlier age of SRE emergence (Cunningham, Vergunst, Turk \& Macrae, in press; Ross et al., 2011; Sui \& Zhu, 2005). In the first of these studies, Sui and Zhu (2005) presented four-, five-, and ten-year-old children with cartoon figures depicted with their own or another child's face. The figures were shown pointing at an object and participants were asked, "Who is pointing at the [e.g., tree]?”. Free recall tests demonstrated an SRE in the five- and ten-year-old children, who remembered more objects when 'self' was pointing. The younger children did not show an SRE in item recall, and no self-advantage was evident across any age-group when source memory (i.e., 
who was pointing at the object?) was assessed. These findings were presented as evidence for the emergence of self-referential encoding around the age of five-years.

Extending Sui and Zhu's work, Ross et al. (2011) examined three- and four-year-old children's memory for objects associated with themselves or another person. Associations were created through various means including action generation by self and other, actions depicted on self or other (e.g., objects presented on the referent's photograph as if they were being used), and ownership by self or other. Unlike Sui and Zhu, Ross et al. found that children as young as $3 \frac{1}{2}$ years could show a memory advantage for objects associated with self. However, this effect did not emerge consistently across different forms of self-object association. Some encoding contexts elicited a SRE in recognition that decreased with age, but did not produce a SRE in free recall (e.g., Experiment 3; see also Cunningham et al., in press). In contrast, other tasks did elicit a SRE in free recall, but found that this increased with age (e.g., Experiment 7). Interestingly, in both Ross et al.'s study and Sui and Zhu's (2005) experiments, controlling for ceiling effects effectively eradicated developmental increases in SRE. While these studies therefore provide preliminary evidence that a stable SRE may emerge in early childhood, it is clear that there remains a need for a systematic examination of the effect.

Consideration of the mixed findings from SRE studies gives rise to two important conclusions. First, self-referential memory effects can be found in young children if ageappropriate, concrete encoding tasks are utilised. Second, developmental patterns of changing SREs are complex and present an empirical challenge. In particular, it is important to develop a paradigm that cleanly explores the effects of self-referencing at encoding, maintaining the important elements of the SRE paradigm but adopting an age-appropriate design. The current inquiry aims to meet these needs. First, we consider the developmental changes in memory that may influence the emergence of early SREs. 


\section{Developing Memory Systems}

The adult SRE relies on the creation of rich memory representations, whereby incoming information is elaborated with autobiographical detail and organised within the selfknowledge framework (Klein \& Kihlstrom, 1986; Klein \& Loftus, 1988; Symons \& Johnson, 1997). Adding to this elaboration, self-referential encoding is also characterised by episodic binding (i.e., representations are associated with details of the encoding event). Compared with encoding information about others, participants are more likely to remember contextual, supporting material about information encoded with reference to self (Conway \& Dewhurst, 1995a, Conway, Dewhurst, Pearson, \& Sapute, 2001; Van den Bos et al., 2010).

These characteristics of self-referential encoding may account for some reports that the SRE increases with development (Halpin et al., 1984; Ray et al., 2009), because younger children are less likely to produce contextualised representations of incoming information. In particular, research suggests that young children have difficulty creating associative links between constructs in memory (Wimmer \& Howe, 2009), and with binding features of an episode together (Newcombe, Drummey, Fox, Lie, \& Ottinger-Alberts, 2000; Raj \& Bell, 2010). Thus while children as young as three show some evidence of episodic memory, this increases markedly by six years and continues to improve across childhood (for review see Raj \& Bell, 2010), probably as a result of cortical maturation and developing executive abilities (e.g., Brocki \& Bohlin, 2004). Putting this evidence together, it seems plausible to predict that young children may show SREs in recognition memory, but that the characteristic episodic nature of adult SREs may be dependent on developmental changes in cognition across childhood (see Sui \& Zhu, 2005).

A second relevant mnemonic change is the development of autobiographical memory across childhood. This encompasses semantic knowledge about one's own characteristics and personal details, as well as episodic recollection of personal experiences (Conway \& 
Pleydell-Pearce, 2000). It seems reasonable to assume that younger children, having been subjected to fewer life experiences, would have recourse to a poorer autobiographical knowledge structure than older children. This means that the potential to enrich incoming information will be reduced in young children. Further, research suggests that the information contained in a child's self-concept undergoes qualitative shifts between early and late childhood, changing from a focus on concrete features and possessions (e.g., "I live on Bell Street", "I have a bike") to abstract characteristics (e.g., "I am ambitious", "I am shy") (Eder, 1989; Montemayor \& Eisen, 1977). This change is critical because the standard paradigm applied in most developmental SRE research requires the children to be able to process abstract character traits in relation to themselves or another person. Given this developmental pattern, tasks exploiting concrete rather than abstract processing should provide a more appropriate method of exploring memory effects in young children.

\section{The Current Inquiry}

A concrete encoding task was designed to explore the impact of self-referencing on memory in early childhood. In three experiments, three different samples of four to six-yearold children were asked to encode concrete objects with reference to themselves or another referent. In Experiment 1, recognition memory was used to assess whether encoding objects while thinking about themselves (e.g., “do you like apples?”) elicits a memory advantage over objects encoded about others (e.g., “would he[she] like balloons?”). Experiment 2 replicated this design but assessed source memory for self- and other-referenced objects. Finally, Experiment 3 explored whether conscious evaluation of the self- or other-concept is required to drive SREs in childhood. Together, these experiments provide a thorough examination of the emergence and development of SREs in memory across childhood. 


\section{Experiment 1: Evaluative Encoding Effects}

In Experiment 1 we developed a variation on the standard adult evaluative encoding task for use with four- to six-year-old children. Accordingly, rather than evaluating abstract character traits, children were required to evaluate concrete and highly-familiar items such as toys and household objects. The self-reference manipulation was achieved by asking the children to decide whether they or an unfamiliar other-referent would like each item. It was expected that young children would show a SRE, with more items evaluated about self being correctly recognised than items evaluated with reference to the other person. It was also expected that both overall memory performance and the size of the advantage for selfreferenced items would increase with age, as the children become more adept at elaborative encoding (Raj \& Bell, 2010; Wimmer \& Howe, 2009).

\section{Method}

\section{Participants and Design}

The sample comprised 53 children aged four to six years, including 17 four-year-olds (41.2\% male, age range 51 - 59 months, mean age 55.7 months), 18 five-year-olds ( $44.4 \%$ male, age range 61 - 70 months, mean age 65.3 months), and 18 six-year-olds (50\% male, age range 72 - 93 months, mean age 76.7 months). All participants spoke English as a first language and were pupils at local nurseries and primary schools. The children were tested with the written consent of a parent or guardian and the research was approved by the University of Aberdeen's Psychology Ethics Committee. The experiment had a mixed design with one repeated-measures (Referent: self or other) and one between-subjects (Age: four, five, or six years) factor.

\section{Procedure and Stimulus Materials}

The experimenter met each child twice. In the first meeting, a digital color photograph of the child's face was taken. Before seeing the child for a second time, the experimenter 
cropped the photograph using picture editing software, creating a $250 \times 250$ pixel (72 dpi) image of the child's face on a transparent background. This picture was used to cue selfreferencing in the experimental task. Facial photographs of a five-year-old boy ('Andrew') and five-year-old girl ('Amy') who were unknown to the participants were modified in the same way to create male and female other-referent cues.

The second meeting (within two weeks of the first) comprised the experimental task. The child sat at a table facing a 15" touch-screen monitor (connected to an Apple Macintosh laptop computer). The experimenter sat beside the child, in front of the laptop. The experiment was run using PsyScope experimental software (Cohen, MacWhinney, Flatt, \& Provost, 1993), and consisted of an encoding task followed by a recognition memory test.

Encoding task. In the encoding task (summarised in Figure 1), a face was presented on a white background in the centre of the touch-screen monitor for $2000 \mathrm{~ms}$. In half of the trials, this was the child's own face ('self-referent' trials). The other half comprised 'otherreferent' trials, in which the face of the unknown, opposite-sex child was presented (i.e., 'Andrew' for female participants, 'Amy' for male participants). Opposite-sex other-referents were used in order to minimise the chances of participants simply projecting their own likes and dislikes onto the other-referent. In total, 24 self-referent and 24 other-referent trials were presented in an order randomised by the software.

$500 \mathrm{~ms}$ after the onset of the face, an object was shown in a box to the left or right of the face. The objects comprised 48 toys and everyday household items (e.g., chair, kettle), and were presented as $250 \times 250$ pixel ( $72 \mathrm{dpi}$ ) color photographic images on a white background. The presented objects were taken from a total of 72 that were divided into three lists matched on object type (e.g., games, cuddly toys, furniture), syllabic length, stereotypic owner-gender and attractiveness to age-matched children. For each child, one of the three lists was presented in self-referent trials, one was presented in other-referent trials, and the 
third was reserved to be used as foils in the subsequent recognition memory test. The use of these lists was counterbalanced across participants.

The children's task was to evaluate the object with reference to the faces. Specifically, they were asked, "Would you [Andrew or Amy] really, really like this object, or would you [he or she] not be very fussed about it?". The two images (i.e., face and object) remained onscreen together for $1500 \mathrm{~ms}$, then a $100 \mathrm{~ms}$ blank inter-stimulus interval preceded presentation of two yellow circle 'buttons' depicting a smiley and neutral face respectively (see Fig. 1). The children were asked to touch either the smiley face or neutral face button to indicate the outcome of their evaluation. Following the child's response, the faces disappeared and a blank 1000ms interval preceded presentation of the next trial.

Before beginning the experimental trials, each child was given three practice trials (one self-referent and two other-referent trials) to ensure that they recognised their own face, understood the task instructions, and were able to evaluate their own and the other referent's likely feelings towards the objects. All the children recognised themselves and were able to follow the task instructions. After the practice trials, the children were encouraged to keep attending to the items onscreen to avoid missing any objects, and were asked not to talk during the task. After completing the 48 experimental trials, the children were praised for their concentration before being introduced to the recognition task.

Recognition task. In the recognition memory test, the object images were presented individually in the centre of the screen. All 72 items were presented (i.e., 24 self-referent, 24 other-referent, and 24 previously unseen foils) in an order randomised by the experimental software. Participants were asked simply whether each object had been presented during the encoding task. The experimenter told the children, "Don't worry if you're not sure of your answer - it's okay to have a guess", and recorded the child's verbal response of 'Old' or 'New' on the laptop via a key press. Following the experimenter-entered response, the object 
disappeared and a 1000ms inter-trial interval preceded presentation of the next object. On completion of the recognition task, each child was thanked and returned to class.

\section{Results and Discussion}

The .05 level of confidence was used for all statistical tests. Effect sizes are reported as partial eta squared (partial $\eta^{2}$ ). To analyse the recognition memory data, raw hit rates (i.e., proportion of Old items correctly identified as $O l d$ ) and false alarm rates (i.e., proportion of New items incorrectly identified as $O l d$ ) were calculated (Table 1). Raw scores were then corrected for guessing by subtracting the proportion of false alarms from the proportion of correctly recognised Old items for each participant. As can be seen from Table 1, the younger children had a relatively high false alarm rate, consistent with previous research (see Lloyd, Doydum, \& Newcombe, 2009). This may reflect young children's lower ability to bind features at encoding, which allows discrimination of the encoding event (Lloyd et al., 2009) from other memories. Alternatively it may result from younger children's higher susceptibility to social desirability (i.e., children saying they remember an item to please the experimenter - see Crandall, Crandall, \& Katkovsky, 1965).

The corrected recognition scores were submitted to a mixed 2 (Referent: self or other) x 3 (Age: four, five, or six years) analysis of variance (ANOVA). This confirmed a significant increase in memory performance with age $\left(F(2,50)=22.61, p<.001\right.$, partial $\eta^{2}=$ .48). There was also a significant effect of Referent $\left(F(1,50)=23.15, p<.001\right.$, partial $\eta^{2}=$ .32), with self-referent trials eliciting higher recognition memory (see Fig. 2). The interaction between Age and Referent was not significant $\left(F(1,52)=1.34, n s\right.$, partial $\left.\eta^{2}=.05\right)$.

At encoding, participants were more likely to give a 'happy' than 'neutral' responses overall $(64.9 \%$ and $35.1 \%$ of responses respectively, $t(52)=8.19, p<.001)$, and to provide more 'happy' responses in the self condition $(67.8 \%)$ than the other condition $(62.1 \% ; t(52)=$ $2.12, p<.05)$. However, the proportion of items eliciting a 'happy' response that were 
subsequently correctly recognised (mean $.84, S D .14$ ) did not differ from the proportion of 'neutral' items subsequently recognised (mean .83, $S D .15), t(52)=0.52, p=.608$ ).

The pattern of memory performance in the current experiment suggests that young children can show an evaluative SRE in memory if age-appropriate stimuli are presented. In the current paradigm, the children had the opportunity to elaborate on incoming self- and other-referent items with stored knowledge about familiar, concrete objects. Interpreting the results through the standard adult account of the SRE (Symons \& Johnston, 1997), the pattern of memory performance could be driven by increased elaboration and organisation supported by the self-knowledge framework. The children had access to knowledge about their own likes and dislikes, as well as autobiographical memories with which to enrich the items evaluated with reference to themselves. As discussed above, attentional processes could also play a role in producing more elaborate memory traces for self-referenced items.

The current data did not support the idea that the SRE increased with development. Indeed, there was a (non-significant) tendency for the SRE to decrease with age (see Table 1, for similar findings see Cunningham et al., in press; Ross et al., 2011). This may be explained by the fact that the older children were performing close to ceiling (e.g., 4 of the 18 six-yearold children were at ceiling for the self-referenced items, compared with none of the fouryear-olds). To reduce the potential for ceiling effects to influence memory performance, we therefore introduced a delay between the encoding and test phase in a second experiment. An additional motivation for Experiment 2 was that an analysis of recognition hits provides a limited measure of memory performance that can be driven by mere familiarity (see Conway et al., 2001). The SRE is particularly associated with episodic recollection, in which features of the encoding event are bound in a rich representation (Conway \& Dewhurst, 1995a; Conway et al., 2001). Indeed, Conway and Dewhurst suggest re-labelling the SRE as the 'self-reference recollection effect' (SRRE) to reflect this pattern. Accordingly, 
source memory judgements that tap episodic recollection (Johnson, Hashtroudi, \& Lindsay, 1993) have been shown to distinguish self- from other-referent encoding in both younger and older adults (Cunningham, Van den Bos \& Turk, 2011; Glisky \& Marquine, 2009; Hamami, Serbun \& Gutchess, 2011; Leshikar and Duarte, 2012; Van den Bos et al., 2010). This may not be the case in early childhood, however, because the ability to store bound memory representations matures across childhood with executive development, as discussed above (Raj \& Bell, 2010). In order to explore the type of memorial representation elicited by selfreferential encoding in children, Experiment 2 also included a measure of source memory. Finally, a measure of executive functioning was included to assess its impact on the children's self-referential cognition.

\section{Experiment 2: Evaluative Encoding Effects: Source Memory}

In Experiment 2, the likelihood of ceiling effects was minimised by introducing a delay between the encoding and test phases of the experiment, and by asking participants to provide source memory judgements at test. The delay comprised completion of a measure of digit span, allowing executive development to be analysed in addition to chronological age. While this widely-used working memory task clearly does not assess the full gamut of executive abilities (see Baddeley, 1992), performance can be used to gauge the development of executive functioning (see Engle, 2002). Following Experiment 1 it was expected that memory would increase with age, and that self-referent items would be remembered more that other-referent items. Following developmental and SRE findings, it was expected that an SRE would be found in source memory, and that this would increase with age and executive ability.

\section{Method}

The sample comprised 55 children aged four to six years, including 18 four-year-olds (33.3\% male, age range 48 - 59 months, mean 55.3 months), 19 five-year-olds (26.3\% male, 
age range 60 - 71 months, mean age 66.3 months), and 18 six-year-olds (61.1\% male, age range $72-82$ months, mean age 75.4 months). All participants spoke English as a first language and were pupils at local nurseries and primary schools. The children were tested with the written consent of a parent or guardian and the research was approved by the University of Aberdeen's Psychology Ethics Committee. The experiment had a mixed design with one repeated-measures (Referent: self or other) and one between-subjects (Age: four, five, or six years) factor.

\section{Procedure and Stimulus Materials}

The stimuli and procedure exactly followed that of Experiment 1 for the first session and the encoding task of the second session (see Fig. 1), with facial image cues of either selfor other-referent being presented with a total of 48 familiar concrete objects. Again, participants were asked to press neutral or smiley face buttons to indicate their evaluation of the object. Following the encoding task, the experimenter administered the British Ability Scales (BAS) II: Recall of Digits Forward subscale (Elliott, Smith, \& McCulloch, 1996). This measure of short-term auditory memory is commonly used as a measure of working memory and is correlated with general executive ability (see Engle, 2002). Completing this task created a break of approximately five minutes between the encoding and recognition tasks.

Presentation of the items in the recognition task followed that of Experiment 1. All 72 items (24 self-referent, 24 other-referent, and 24 previously unseen) were presented individually in the centre of the screen in an order randomised by the software. The recognition test was a one-step source memory test, with participants being asked to respond to each picture with one of the following answers: "New picture", "Shown with me" or "Shown with Andrew [Amy]". As in Experiment 1, the children were told that they could guess if they were not sure of their answer. The child gave a verbal response which was entered into the laptop by the experimenter via a keypress. The object then disappeared and a 
$1000 \mathrm{~ms}$ inter-trial interval preceded presentation of the next object. On completion of the source memory task, the child was thanked and returned to class.

\section{Results and Discussion}

Raw hits rates and false alarm rates are presented in Table 1. As in Experiment 1, recognition scores were corrected for guessing by subtracting the proportion of false alarms (responses of "Shown with me" or "Shown with Andrew [Amy]" to New items) from the proportion of correctly recognised Old items for each participant. Two source recognition scores were also calculated for each participant. The self-referent source score was calculated by subtracting the proportion of 'self' false alarm rate (New items incorrectly identified as "Shown with me") from the proportion of self-referent items correctly identified as "Shown with me". The other-referent source score was scored by subtracting 'other' false alarm rate from items correctly identified as shown with the other referent.

Recognition memory. Although source memory was the dependent variable of interest in the current experiment, recognition data were also analysed for comparison with the results of Experiment 1. Participants' recognition scores were submitted to a mixed 2 (Referent: self or other) x 3 (Age: four, five, or six years) ANOVA which revealed a significant increase in overall memory with Age $\left(F(2,52)=3.53, p<.05\right.$, partial $\left.\eta^{2}=.12\right)$. Further, self-referent items were significantly more likely to be remembered than otherreferent items $\left(F(1,52)=10.19, p<.005\right.$, partial $\left.\eta^{2}=.16\right)$, regardless of age (interaction: $F$ $(2,52)=1.67, n s$, partial $\left.\eta^{2}=.06\right)$. This pattern of results replicates the findings of Experiment 1, suggesting that a robust SRE can be demonstrated in early childhood recognition memory.

At encoding, participants were more likely to give a 'happy' than 'neutral' response $(61.8 \%$ and $38.2 \%$ of responses respectively, $t(54)=5.23, p<.001)$. Like Experiment 1 , there was also a tendency for participants to provide more 'happy' responses in the self 
condition $(64.6 \%)$ than the other condition $(59.1 \% ; t(54)=2.26, p<.05)$. However, following the pattern of Experiment 1 this did not impact on subsequent memory (mean 'happy' item recognition: .88 (SD .09) mean 'neutral' item recognition .86 (SD .16); $t(54)=$ $1.62, p=.11)$.

Source memory. A mixed 2 (Referent: self or other) x 3 (Age: four, five, or six years) ANOVA revealed a similar pattern of results for participants' source memory. The effect of age was significant $\left(F(2,52)=3.34, p<.05\right.$, partial $\left.\eta^{2}=.11\right)$, with memory performance increasing between four and six years. There was also a significant effect of referent $\left(F(1,52)=12.15, p<.001\right.$, partial $\left.\eta^{2}=.18\right)$, reflecting a tendency for self-referent items to be linked with their correct source more often than other-referent items (see Fig. 3). As in recognition memory performance, this SRE was consistent across the age groups (Referent x Age interaction: $F(2,52)=0.78, n s$, partial $\left.\eta^{2}=.03\right)$.

Developmental patterns. Correlations were calculated to examine the impact of chronological age and cognitive ability on the memory advantage for self-referenced items. A 'self-referential advantage' score was calculated by subtracting the recognition score for other-referent items from that of self-referent items. Separate correlations were calculated for Recognition and Source data. Chronological age in months was not significantly correlated with the memory advantage for self-referent items in either recognition $(r(55)=-0.12, p=$ $.39)$ or source memory $(r(55)=-0.01, p=.92)$, confirming the pattern identified in the ANOVAs with this more sensitive measure of age. Two participants did not complete the measure of executive functioning ability (the Recall of Digits Forward sub-test of the BAS), because they asked to stop. Recall of Digits performance was transformed into an ability score, following the BAS administration procedure (see Eliot et al., 1996). Like chronological age, this measure was not found to correlate with the memory advantage for self-referent items in either recognition $(r(53)=-0.046, p=.75)$ or source memory $(r(53)=-0.051, p=$ 
.72). Together, these correlations suggest that the observed SREs in memory are robust and seemingly unrelated to changes in age or cognitive ability.

The absence of a developmental increase in the size of the SRE in source memory is somewhat surprising. The older children in our sample were expected to remember more item-referent pairings, in line with their developing binding abilities (see Lloyd et al., 2009; Raj \& Bell, 2010). The current findings suggest that the self-referential encoding context is a sufficiently powerful encoding tool to allow even young children to store a strong memory trace. Complicating this argument, more other-referent items were misattributed to self than self-referent items were misattributed to other $(F(1,52)=8.39, \mathrm{p}<.01)$, regardless of age (interaction $F(2,52)=.09, n s)$. This suggests that the children had a tendency to erroneously assume familiar items were self-referent, an interesting pattern that is somewhat counterintuitive given the type of recollection typically associated with SREs. Fully exploring this additional potential source of self-referential bias in a two-step (recognition, source) memory test (see Conway \& Dewhurst, 1995b) could be of great value in future research.

The finding of an early source memory SRE may be due to specific features of selfreferential encoding being functionally distinct from other-referent processing. Rather than simply increasing depth of processing (Craik \& Lockhart, 1972), self-referent encoding is characterised by particular features such as episodic binding (Conway \& Dewhurst, 1995a) and increases in both elaboration and organisation at encoding (Klein \& Kihlstrom, 1986; Klein \& Loftus, 1988). Further, neuroimaging research suggests that self-referential processing activates a specific midline cortical network that is not associated with either other-referent cognition nor increased depth of processing (Kelley, Macrae, Wyland, Caglar, Inati, \& Heatherton, 2002; Northoff, Heinzel, de Greck, Bermpohl, Dobrowolny, \& Panksepp, 2006). These memory-supporting features of self-referential encoding may help to 
explain why even young children are able to show the SRE in both recognition and source memory.

This pattern speaks to recent work suggesting that SREs may be driven by low-level, automatic responses to self-cues, as well as elaboration and organisation by the selfknowledge framework (see Turk et al., 2008; Ross et al, 2011). In particular, neuroimaging research has suggested that attention might be the driving mechanism, with self-cues eliciting attentional responses that could support enhanced encoding (Gray et al., 2004; Turk, van Bussel, Waiter et al., 2011; Turk, van Bussel, Brebner et al., 2011). If this mechanism is a critical driver of SREs, it would account for the finding of the current study that neither developing executive ability nor increasing self-knowledge with age contributed to the size of the memory advantage for self-referenced items. Young children's extant self-concept and self-recognition might be sufficient to elicit an automatic attentional response to self-cues, eliciting a SRE without relying on elaboration by self-knowledge.

This reasoning raises the interesting question of whether SREs require activation of the self-knowledge framework at all. In the standard SRE paradigm, the trait evaluation task requires participants to consciously consider the self- and other-concept in relation to the traits during encoding. In Experiments 1 and 2, evaluation of the child's own and another's likes and dislikes requires a similar self- and other-evaluation. However, such effortful consideration may not be a necessary prerequisite to SRE elicitation. Turk et al. (2008) demonstrated that when self-images are paired with to-be-encoded stimuli, this elicits a memory advantage compared to stimuli paired with images of other people. In this study, half of the participants were simply asked to monitor the location of the stimuli; the identity of the image was task-irrelevant ('incidental' encoding condition). The other participants evaluated the stimuli with reference to the person shown in the image ('evaluative' encoding condition). The procedure, stimuli, and responses for the two conditions were identical, so memory 
performance could be directly compared. This comparison revealed that a significant SRE was elicited in both the incidental and evaluative encoding conditions, but that the effect was more pronounced in the latter.

This pattern was interpreted as suggesting that in both conditions, an increase in automatic responses to self-cues (compared to other-cues) drew attention to the self-paired stimuli, enhancing encoding. However there was an additive effect of consciously considering the self that may have further enhanced self-referential encoding in the evaluative condition, by providing access to the elaborative potential of autobiographical knowledge. To examine whether this intriguing pattern of adult SRE elicitation would also emerge in early childhood, a third experiment was designed in which participants completed an encoding task involving 'incidental' pairing of the self or another referent with stimuli.

\section{Experiment 3: Incidental Encoding Effects}

Following the design of Turk et al.'s (2008) study, Experiment 3 adapted the design of Experiment 2 such that the procedure, stimuli, and responses were matched, but the children's task was to monitor object location (left or right), rather than to evaluate the object against a referent. Following the findings of Experiment 2, it was expected that this incidental encoding procedure would elicit stable SREs in both recognition and source memory performance.

\section{Method}

\section{Participants and Design}

The sample comprised 56 children aged four to six years, with 20 four-year-olds (45.0 $\%$ male, age range 48 - 59 months, mean age 52.0 months), 18 five-year-olds (61.1\% male, age range 60 - 71 months, mean age 67.2 months), and 18 six-year-olds (55.6\% male, age range $72-83$ months, mean age 77.7 months). All participants spoke English as a first language and were pupils at local nurseries and primary schools. The children were tested 
with the written consent of a parent or guardian and the research was approved by the University of Aberdeen's Psychology Ethics Committee. The experiment had a mixed design with repeated-measures (Referent: self or other) and between-subjects (Age: four, five, or six years) factors. The dependent variables were recognition memory and source memory.

\section{Procedure and Stimulus Materials}

The stimuli and procedure exactly followed that of Experiment 2 for the encoding and test phases of the experiment, with one critical exception. Instead of being asked to evaluate each object with reference to self or the other referent, the children were asked simply to report on which side of the screen the object had been presented. As Fig. 1 shows, this involved presenting two empty yellow circles as response buttons, with no neutral or smiley faces. The size, color, brightness, and position of these 'left' and 'right' buttons were exactly matched with the face response buttons presented in Experiments 1 and 2. As in Experiment 2, when all the items had been presented, participants completed the digit span task, then a one-step source memory test including all 72 items (24 self-referent, 24 other-referent, and 24 previously unseen items), before being thanked and returned to class.

\section{Results and Discussion}

As in Experiment 2, participants' recognition and source memory data were corrected for guessing by subtracting the relevant false alarm rate from the correctly recognised Old items. Raw hit, source, and false alarm rates can be found in Table 1. The encoding task elicited a low mean error rate of $5.7 \%$ so target items eliciting errors at encoding were not excluded from the memory analysis.

Recognition memory. The data were submitted to a 2 (Referent: self or other) x 3 (Age: four, five, or six years) ANOVA, from which the only significant pattern to emerge was that self-referent items were more likely to be remembered than other-referent items ( $F$ $(1,53)=10.09, p<.005$, partial $\left.\eta^{2}=.16\right)$. Neither the main effect of Age $(F(2,53)=2.20, n s$, 
partial $\left.\eta^{2}=.08\right)$ nor the Age X Referent interaction $\left(F(2,53)=0.06, n s\right.$, partial $\left.\eta^{2}=.002\right)$ were significant.

Source memory. Participants' source memory scores were also submitted to a mixed 2 (Referent: self or other) x 3 (Age: four, five, or six years) ANOVA. This revealed a significant increase in performance with age $\left(F(2,53)=3.91, p<.05\right.$, partial $\left.\eta^{2}=.13\right)$ and a strong effect of Referent, with self-referent items being associated with better source memory than other-referent items $F(1,53)=13.05, p<.001$, partial $\eta^{2}=.20-$ see Fig. 4$)$. The interaction between the factors was non-significant $\left(F(2,53)=0.19, n s\right.$, partial $\left.\eta^{2}=.007\right)$.

Developmental patterns. As in Experiment 2, the relationship between the selfreferent memory advantage in both recognition and source memory was examined by calculating a self-referential advantage score (recognition scores for other-referent items subtracted from that of self-referent items). Replicating the pattern found in Exp. 2, there was no relationship between age in months and the self-referential memory advantage in either recognition $(r(56)=0.03, p=.82)$ or source memory $(r(56)=0.04, p=.77)$. Similarly, cognitive ability as gauged by the Recall of Digits Forward test (transformed into ability scores) had no relationship with the self-reference advantage in either recognition $(r(56)=$ $0.12, p=.38)$ or source memory $(r(56)=-0.11, p=.43)$. Following the pattern of memory performance in Exp. 2, these findings suggest that the children's increasing age and developing executive abilities did not impact on their ability to preferentially encode selfreferential information.

\section{Experiments 2 and 3: Additional Analysis}

The pattern of self- and other-referent encoding revealed by both recognition memory and source monitoring scores suggests that incidental associations between self and external stimuli elicit similar effects to evaluative processing. In order to more effectively gauge the relative impact of incidental and evaluative SREs in early childhood, an additional analysis 
was performed on the data collected in Experiments 2 and 3 together. Combining the data from Experiments 2 and 3 produced a sample of 111 children including 38 four-year-olds (39.5\% male, age range 48 - 59 months, mean age 53.6 months), 37 five-year-olds (43.2 \% male, age range 60 - 71 months, mean age 66.7 months), and 36 six-year-olds (58.3\% male, age range $72-83$ months, mean age 76.6 months).

Recognition memory. Participants' hit scores were submitted to a mixed 2 (Encoding condition: Evaluative or Incidental) x 2 (Referent: self or other) x 3 (Age: four, five, or six years) ANOVA. All three main effects were found to be significant, with memory being better under Evaluative than the Incidental encoding conditions $(F(1,105)=18.02, p<.001$, partial $\left.\eta^{2}=.15\right)$, increasing with age $\left(F(2,105)=5.58, p<.005\right.$, partial $\left.\eta^{2}=.10\right)$, and being better for self-referent than other-referent items $\left(F(1,105)=20.2, p<.001\right.$, partial $\left.\eta^{2}=.16\right)$. Of particular note, the impact of referent on memory was consistent across the two experiments (see Fig. 5) with no evidence of an interaction between Encoding condition and Referent $\left(F(1,105)=0.07, n s\right.$, partial $\left.\eta^{2}=.001\right)$. No other interactions between the variables approached significance.

Source memory. An additional analysis comparing source memory across the two encoding conditions was also performed. This revealed that source memory elicited an identical pattern of results to Recognition memory, with the three factors each having a significant effect in the same direction (Encoding condition: $(F(1,105)=25.60, p<.001$, partial $\left.\eta^{2}=.20\right)$, Age $\left(F(2,105)=5.85, p<.005\right.$, partial $\left.\eta^{2}=.10\right)$, Referent $(F(1,105)=$ 24.84, $p<.001$, partial $\eta^{2}=.19$ ). Again, no interactions approached significance.

This analysis provides an interesting contrast to the findings reported by Turk et al. (2008). Turk et al. also found that both evaluative and incidental encoding elicited a selfreferential advantage, but that the effect was greater in the evaluative condition (eliciting a statistically significant interaction between the factors Referent and Encoding condition). In 
contrast, the current analysis reveals a consistent SRE across the two conditions, with no indication of an interaction between the factors; indeed the $F$-value of the interaction between Referent and Encoding condition was almost at zero.

This difference between the adult and childhood pattern of performance ties in neatly with the account for the lack of any developmental increase in the SRE offered above. If the SRE in early childhood is driven by automatic responses to self-cues such as attention, as suggested by their lack of developmental increase, then these will be elicited to a similar degree in both evaluative and incidental encoding conditions. It is possible that any additional memory effect elicited by self-referencing in the evaluative condition may require more mature executive processing, with support from autobiographical memory. Thus, the additional self-referential advantage elicited by evaluative encoding may only emerge later in childhood, as previous findings using standard SRE paradigm have suggested (Halpin et al., 1984; Ray et al., 2009). While this possibility is theoretically intriguing, it is purely speculative and requires investigation with a range of evaluative self-referential tasks.

\section{General Discussion}

The current inquiry was designed to provide a thorough assessment of the selfreference effect on memory in young children. In three experiments, four-, five- and six-yearold children showed a clear memory advantage for stimuli encoded with reference to self, relative to stimuli encoded with reference to another person. In Experiments 1 and 2, this effect was found in an evaluative encoding condition ("would you [Amy] like this item"). In Experiment 3, the self-referential encoding advantage was also observed for a task that did not require self-evaluation (“where did the item appear?”). Together, these findings suggest that the SRE is already robust and influential in early childhood.

As well as a reliable SRE, several interesting patterns of memory performance emerged from the three experiments. First, the SRE was largely consistent across the age- 
range studied (four- to six-years), and uncorrelated with working memory ability. This contrasts with previous SRE studies based on the trait evaluation task (Halpin et al., 1984; Ray et al., 2009), in which children showed an increase in SRE between middle to late childhood (beyond which the level is equivalent to an adult SRE). However, other researchers have reported a stable SRE from five years upwards (Pullyblank et al., 1985, Bennett \& Sani, 2008). The differing findings from the trait-evaluation task may reflect varying task difficulty across studies, raising the importance of a concrete encoding task that can be applied across ages. Research focusing on early childhood has reported a range of stable SREs, SRE increases and decreases in SRE across development. These findings are difficult to interpret because the studies each examine a different aspect of self-referencing: referent identification (Sui \& Zhu, 2005), action generation or depiction (Ross et al., 2011), and ownership (Cunningham et al., in press; Ross et al., 2011). Again, the experiments in the current study offer a much-needed systematic examination using an age-appropriate version of the standard SRE task.

The stability of the effect identified in all three of the current experiments requires explanation. The most parsimonious is that the SRE is an age-invariant effect. While this account is arguably the most compelling, alternative explanations cannot be ruled out. One possibility is that children's developing self-concept did not impact on their level of SRE because the task did not require them to make use of mature or extensive self-awareness (Montemayor \& Eisen, 1977). The questions are relatively easy to answer with respect to very young children's existing knowledge (indeed this was a deliberate feature of the design). It may be that using more difficult questions would elicit an upward developmental trend, even within early childhood, as children would have the potential to produce increasingly elaborate representations associated with the self-concept. 
An intriguing alternative possibility is that developing systems may interfere with one another in early childhood SREs. In particular, on the basis of diminishing egocentricity it could be predicted that young children would show decreasing self-focus and increasing interest in others across the 4-6 year age range (Kesselring, Müller, 2011, Piaget, 1926/1959), resulting in decreasing SREs at this stage (a pattern suggested by Cunningham et al, in press). However, the evidence of an increase in the size of the SRE later in childhood (Halpin et al., 1984; Ray et al., 2009) suggests that the SRE increases with development as selfconcepts become increasingly rich and mature. The fact that no SRE change was found in the current experiments may therefore be because diminishing egocentricity cancels out the influence of self-concept development.

A second interesting pattern in the current study is that an age-invariant SRE emerged in both recognition (Experiments 1-3) and source memory judgements (Experiments 2 and 3). The SRE is associated with episodic recollection, in which features of the encoding event are bound in a rich representation (Conway \& Dewhurst, 1995a; Conway et al., 2001; Van den Bos et al., 2010). These memories can be assessed by judgements of source as well as recollection (see Yonelinas, 1999), so the current finding that SREs emerged in source memory is consistent with previous research. Less consistent is the absence of a developmental increase in source memory performance between four and six years. Previous research with children suggests that the ability to bind features of the encoding event is a developing skill that depends on increasing executive capacity (see Raj \& Bell, 2010). This did not emerge in the current study however: the children were equally able to produce bound representations of the to-be-encoded item and the item context (indicated by accurate source memory judgements) across the age-range.

A compelling explanation for the younger children's ability to effectively judge source comes from automatic responses to self-cues. One reason for the encoding advantage 
elicited by self-referencing in adults is that the self elicits physiological arousal and attracts attention (Bargh, 1982; Cherry, 1953; Gray et al., 2004; Sui, Zhu, \& Han, 2006; Turk, van Bussel, Waiter et al., 2011; Turk, van Bussel, Brebner et al., 2011). Increases in arousal and attention have a predictable effect on memory: the creation of bounded episodic memories that are likely to be subsequently recalled (for review see Mather, 2007). While much of the research in this area has focused on the processing of emotional stimuli, we would suggest that self-referential encoding shares many of the same encoding features. It is therefore plausible that automatic responses to self cues, which should be relatively stable across development, underlie the children's source memory performance in the current study. The absence of a relationship between the children's self-referential advantage and their working memory supports the reasoning that automatic responses support the SRE at this early stage.

Related to this point, the third main finding from the current inquiry is that the children showed a similar SRE advantage under both evaluative (Experiments 1 and 2) and incidental (Experiment 3) encoding conditions. The incidental encoding task is a minimal form of self-referencing, where conscious self-processing is not required and any increase in memory performance is likely to be driven by the automatic responses to self-cues described above (Turk et al., 2008). If children's SRE depends on this automatic attentional response, then it would be expected that evaluative and incidental encoding tasks would evoke a similar level of self-referential memory advantage. This pattern is exactly what emerged in the current inquiry (Experiments 2 and 3). Turk et al.'s (2008) comparison of adult incidental and evaluative SREs revealed a self-referential memory advantage in both encoding conditions, but produced a larger effect in evaluative encoding. Conscious self-reflection in the evaluative condition therefore provided an additional source of elaborative or organisational support at encoding in the adults (Klein \& Kihlstrom, 1988; Klein \& Loftus, 1986, Symons \& Johnson, 1997). In children, we did not find any evidence of an additional self-referential 
advantage gained by conscious self-evaluation (although evaluation gave rise to better memory performance on the whole, due to increases in depth of processing (Craik \& Lockhart, 1972)). Firm conclusions cannot be drawn on the basis of a single evaluative task, as it is conceivable that the current measure failed to evoke a sufficient degree (or difficulty) of self-evaluation. However, the data are consistent with the idea that low-level, automatic processes are underlying the SRE at this early stage.

Interestingly, a distinction between the evaluative processing system and one based on automatic responses echoes many philosophical and psychological distinctions of selffunctioning. There have been proposals to consider the self in terms of (at least) two functionally distinct concepts: an 'I', who knows about a 'Me' (James, 1890). These senses of self have been variously incarnated as 'subjective' and 'objective' (Duval \& Wicklund, 1972), 'core' and 'experiential' (Northoff et al., 2006), and 'proto-' and 'autobiographical' (Damasio, 1999). Although individual theorists' definitions vary, there is a consistent pattern of dividing the self into a low-level, physical sense, and a higher order, conscious and autobiographically-aware component. The finding that two functionally different aspects of self appear to contribute to the SRE in memory (i.e., automatic responses, or elaboration by the self-knowledge framework) fits neatly within these philosophical conceptualisations.

In addition to these theoretical considerations, there are notable practical implications of the current work. For example, if self-referencing does impact on encoding and memory across childhood as the current inquiry suggests, then using the self as an encoding context could be an effective teaching strategy. Activating the self at encoding (e.g., generating selfreferential sentences) may helping learners to attend to incoming information and produce elaborate representations, increasing chances of successful retrieval. However, it is important to note that there may be negative ramifications of identifying methods to improve children's memory. In particular, such methods can be misused in the legal system. 'Supplementary 
techniques' designed to enhance recall can significantly increase the risk of errors in children's testimony, with very serious consequences for both victims and suspects (for review see Brown, 2011). Considerable field study and interview research must be conducted before any memory enhancement technique is considered for use in context of children's testimony.

In addition to this caveat, a limitation of the current work is that it charts development across a narrow age range (four- to six-years). This range was chosen because it corresponds with the period at which the effects of the self on memory are particularly unclear. However, the subsequent developmental trajectory of incidental and evaluative SREs across childhood is also poorly understood and subject to conflicting data, meaning that this key influence on cognition is unchartered. Applying age-appropriate paradigms across the gap in the literature (i.e., between early and late childhood) when both the self-concept and memory systems are maturing significantly would provide much-needed clarity. Systematically assessing both evaluative and incidental SREs during this period would also provide a chance to determine when the self-referential advantage elicited by evaluative encoding accrues an additional memory boost over that elicited by incidental encoding. The divergent pattern reported in early childhood here, and in adults by Turk et al. (2008), requires replication and explanation. Examining the co-development of potentially related processes (e.g., selfconcept, abstract processing, increases in executive functioning and binding abilities) could also provide an insight into the operations that support the SRE in both adults and children. By offering a solid basis on which to build future research, we believe the current methodology provides the opportunity to further explore the mechanisms underlying the SRE across the lifespan.

A further area of potential interest is the exclusivity of the effect to the self. In adult SRE research, changing the other-referent in SRE tasks to an intimate person (e.g., mother) 
considerably attenuates the effect (Bower \& Gilligan, 1979; Ray et al., 2009; Symons \& Johnson, 1997). Exploring the level of attenuation achieved by replacing a non-intimate other with 'mother' may shed some light on developmental changes in the conceptual overlap between self and others (i.e., if the separation of 'self' from 'mother' grows across childhood and into adolescence, using 'mother' as the other-referent should produce more attenuation in young children than in adolescents). Studying the development of these aspects of selfreferential cognition has the potential to provide valuable clarity and insight into the considerable influence of the self on cognition across development.

\section{Conclusions}

The current inquiry establishes a robust and consistent effect of self-referential encoding in young children. Regardless of whether children were asked to evaluate stimuli with reference to self and another person, or were simply presented with self- or other-cues in a task-irrelevant context, we observed a memorial advantage for items processed in relation to self. These effects emerged in both recognition memory and source memory, and were consistent across four, five, and six-year-old children. These findings suggest that children's self-referential encoding effects have been underestimated to date, and that the self exerts a powerful influence on memory from an early age. 


\section{References}

Baddeley, A. (1992). Working memory: the interface between memory and cognition. Journal of Cognitive Neuroscience, 4, 281-288. doi:10.1162/jocn.1992.4.3.281

Bargh, J. A. (1982). Attention and automaticity in the processing of self-relevant information. Journal of Personality and Social Psychology, 43, 425-436. doi:10.1037/00223514.43.3.425

Bennett, M. \& Sani, F. (2008). Children's subjective identification with social groups: A selfstereotyping approach. Developmental Science, 11, 69-78. doi: 10.1111/j.14677687.2007.00642.x

Bower, G. H., \& Gilligan, S. G. (1979). Remembering information related to one's self. Journal of Research in Personality 13, 420-432. doi:10.1016/0092-6566(79)90005-9

Brocki, K. C. \& Bohlin, G. (2004). Executive functions in children aged 6 to 13: A dimensional and developmental study. Developmental Neuropsychology, 26, 571-593. doi:10.1207/s15326942dn2602_3

Brown, D.A. (2010). The use of supplementary techniques in forensic interviews with children. In M.E. Lamb, D. LaRooy, C. Katz \& L. Malloy (Eds.), Children's Testimony: A Handbook of Psychological Research and Forensic Practice (2nd Ed). Wiley-Blackwell. doi:10.1002/9781119998495.ch12

Cherry, E. C. (1953). Some experiments on the recognition of speech, with one and two ears. Journal of the Acoustical Society of America, 25, 975-979. doi:10.1121/1.1907229

Cohen, J. D., MacWhinney, B., Flatt, M., \& Provost, J. (1993). Psyscope: A new graphic interactive environment for designing psychology experiments. Behavioral Research Methods, Instruments, and Computers, 25, 257-271. doi:10.3758/BF03204507

Conway, M. A. \& Dewhurst, S. A. (1995a). The self and recollective experience. Applied Cognitive Psychology, 9, 1-19. doi:10.1002/acp.2350090102 
Conway, M. A. \& Dewhurst, S. A. (1995b). Remembering, familiarity and source monitoring. Quarterly Journal of Experimental Psychology, 48, 125-140. doi:10.1080/14640749508401380

Conway, M. A., Dewhurst, S. A., Pearson, N., \& Sapute, A. (2001). The self and recollection reconsidered: How a 'failure to replicate' failed and why trace strength accounts of recollection are untenable. Applied Cognitive Psychology, 15, 673-686. doi:10.1002/acp. 740

Conway, M. A. \& Pleydell-Pearce, C. W. (2000). The construction of autobiographical memories in the self-memory system. Psychological Review, 107, 261-288. doi:10.1037//0033-295X.107.2.261

Craik, F. I. M. \& Lockhart, R. S. (1972). Levels of processing: A framework for memory research. Journal of Verbal Learning and Verbal Behavior, 11, 671-684. doi:10.1016/S0022-5371(72)80001-X

Crandall, V. C., Crandall, V. J., \& Katkovsky, W. A. (1965). Children's social desirability questionnaire. Journal of Consulting Psychology, 29, 27-36. doi:10.1037/h0020966

Cunningham, S., Brady-Van Den Bos, M. \& Turk, D. J. (2011) Exploring the effects of ownership and choice on self-memory biases. Memory, 19, 449-461. doi: $10.1080 / 09658211.2011 .584388$

Cunningham, S. J., Turk, J., Vergunst, F., \& Macrae, C. N. (in press). Exploring early selfreferential biases through ownership. British Journal of Developmental Psychology. doi:10.1111/bjdp.12005

Damasio, A. R. (1999). The feeling of what happens: Body and emotion in the making of consciousness. Harcourt Brace, New York.

Duval, T. S., \& Wicklund, R. A. (1972). A theory of objective self-awareness. New York: Academic Press. 
Eder, R. A. (1989). The emergent personologist: The structure and content of 31/2, 51/2, and 71/2-year olds' concepts of themselves and other persons. Child Development, 60, 12181228. doi: $10.2307 / 1130795$

Elliott, C. D., Smith, P. \& McCulloch, K. (1996). The British Ability Scales II. Windsor: NFER-Nelson.

Engle, R. W. (2002). Working memory capacity as executive attention. Current Directions in Psychological Science, 11, 19-23. doi:10.1111/1467-8721.00160

Fasig, L. G. (2000). Toddlers' understanding of ownership: Implications for self-concept development. Social Development, 9, 370-382. doi:10.1111/1467-9507.00131

Glisky, E. L. \& Marquine, M. J. (2009). Semantic and self-referential processing of positive and negative trait adjectives in older adults. Memory, 17, 144-157. doi:10.1080/09658210802077405

Gray, H. M., Ambady, N., Lowenthal, W. T., \& Deldin (2004). P300 as an index of attention to self-relevant stimuli. Experimental Social Psychology, 40, 216-224. doi:10.1016/S0022-1031(03)00092-1

Halpin, J. A., Puff, C. R., Mason, H. F., \& Marston, S. P. (1984). Self-reference encoding and incidental recall by children. Bulletin of the Psychonomic Society, 22, 87-89.

Hamami, A., Serbun, S. J., \& Gutchess, A. (2011). Self-referencing enhances memory specificity with age. Psychology and Aging, 26, 636-646. doi:10.1037/a0022626 James, W. (1890). Principles of psychology. New York: Holt, Rinehart and Winston.

Johnson, M. K., Hashtroudi, S., \& Lindsay, D. S. (1993). Source monitoring. Psychological Bulletin, 114, 3-28. doi:10.1037//0033-2909.114.1.3

Kelley, W.M., Macrae, C.N., Wyland, C.L., Caglar, S., Inati, S., \& Heatherton, T.F. (2002). Finding the self? An event-related fMRI study. Journal of Cognitive Neuroscience, 14, 785-794. doi:10.1162/08989290260138672 
Kesselring, T. \& Müller , U. (2011). The concept of egocentrism in the context of Piaget's theory. New Ideas in Psychology, 29, 327-345. doi:10.1016/j.newideapsych.2010.03.008

Klein, S. B. (2012). A role for self-referential processing tasks requiring participants to imagine survival in the Savannah. Journal of Experimental Psychology: Learning, Memory and Cognition, 38, 1234-1242. doi:10.1037/a0027636

Klein, S. B., \& Kihlstrom, J. F. (1986). Elaboration, organization, and the self-reference effect in memory. Journal of Experimental Psychology: General, 115, 26-38. doi:10.1037/0096-3445.115.1.26

Klein, S. B., \& Loftus, E. M. (1988). The nature of self-referent encoding: The contribution of elaborative and organisational processes. Journal of Personality and Social Psychology, 55, 5-11. doi:10.1037/0022-3514.55.1.5

Leshikar, E. D. \& Duarte, A. (2012). Medial prefrontal cortex supports source memory accuracy for self-referenced items. Social Neuroscience, 7, 126-145. doi:10.1080/17470919.2011.585242

Lewis, M. (2003) The emergence of consciousness and its role in human development. Annals of the New York Academy of Science, 1001, 104-133.

Lewis, M. \& Ramsey, D. (2004). Development of self-recognition, personal pronoun use, and pretend play during the $2^{\text {nd }}$ year. Child Development, 75, 1821-1831. 10.1111/j.14678624.2004.00819.x

Lloyd, M. E., Doydum, A. O., Newcombe, N. S. (2009) Memory binding in early childhood: Evidence for a retrieval deficit. Child Development, 80, 1321-1328. doi:10.1111/j.14678624.2009.01353.x.

Mather, M. (2007). Emotional arousal and memory binding: An object-based framework. Perspectives on Psychological Science, 2, 33-52. doi: 10.1111/j.1745-6916.2007.00028.x Montemayor, R. \& Eisen, M. (1977). The development of self-conceptions from childhood to 
adolescence. Developmental Psychology, 13, 314-319. doi:10.1037/0012-1649.13.4.314

Newcombe, N. S., Drummey, A. B., Fox, N. A., Lie, E. \& Ottinger-Alberts, W. (2000). Remembering early childhood: how much, how, and why (or why not). Current Directions in Psychological Science, 9, 55-58. doi:10.1111/1467-8721.00060

Northoff, G., Heinzel, A., de Greck, M., Bermpohl, F., Dobrowolny, H., \& Panksepp, J. (2006). Self-referential processing in our brain - A meta-analysis of imaging studies on the self. NeuroImage, 31, 440 - 457. doi10.1016/j.neuroimage.2005.12.002

Piaget, J. (1959). Language and thought of the child (3rd edition). London: Routledge \& Kegan Paul.

Pullyblank, J., Bisanz, J., Scott, C., \& Champion, M. A. (1985). Developmental invariance in the effects of functional self-knowledge on memory. Child Development, 56, 1447-1454.

Raj, V. \& Bell, M. A. (2010). Cognitive processes supporting episodic memory formation in childhood: The role of source memory, binding, and executive functioning . Developmental Review, 30, 384-402. doi:10.1016/j.dr.2011.02.001

Ray, R. D., Shelton, A. L., Hollon, N. G., Michel, B. D., Frankel, C. B., Gross, J. J., \& Gabrieli, J. D. E. (2009). Cognitive and neural development of individuated selfrepresentation in children, Child Development, 80, 1232-1242. doi:10.1111/j.14678624.2009.01327.x

Rogers, T. B., Kuiper, N. A., \& Kirker, W. S. (1977). Self-reference and the encoding of personal information. Journal of Personality and Social Psychology, 35, 677-688. doi:10.1037/0022-3514.35.9.677

Ross, J., Anderson, J. R., \& Campbell, R. N. (2011). I remember me: Mnemonic selfreference effects in preschool children. Monographs of the Society for Research in Child Development, 76, 1-102. doi:10.1111/j.1540-5834.2011.00613.x

Sui, J. \& Zhu, Y. (2005). 5-year-olds can show the self-reference advantage. International 
Journal of Behavioral Development, 29, 382-387. doi:10.1080/01650250500172673

Sui, J., Zhu, Y., \& Han, S. (2006). Self-face recognition in attended and unattended conditions: An event-related brain potential study. Neuroreport, 17, 423-427. doi:10.1097/01.wnr.0000203357.65190.61

Symons, C. S., \& Johnson, B. T. (1997). The self-reference effect in memory: A metaanalysis. Psychological Bulletin, 121, 371-394. doi:10.1037/0033-2909.121.3.371

Turk, D. J., Cunningham, S. J., \& Macrae, C. N. (2008). Self-memory biases in explicit and incidental encoding of trait adjectives, Consciousness and Cognition, 17, 1040-1045. doi:10.1016/j.concog.2008.02.004

Turk, D. J., van Bussel, K., Brebner, J. L., Toma, A., Krigolson, O., \& Handy, T. C. (2011). When IT becomes MINE: Attentional biases triggered by object ownership. Journal of Cognitive Neuroscience, 12, 3725-3733.doi:10.1162/jocn_a_00101

Turk, D. J., van Bussel, K., Waiter, G. D., \& Macrae, C. N. (2011). Mine and me: Exploring the neural basis of object ownership. Journal of Cognitive Neuroscience, 11, 3657-3668. doi:10.1162/jocn_a_00042

Van den Bos, M., Cunningham, S. J., \& Turk, D. J. (2010). Mine to remember: The effects of minimal ownership on remembering and knowing. Quarterly Journal of Experimental Psychology, 63, 1065-1071. doi:10.1080/17470211003770938

Wimmer, M. C. \& Howe, M. L. (2009). The development of automatic associative processes and children's false memories. Journal of Experimental Child Psychology, 104, 447-465. doi:10.1016/j.jecp.2009.07.006

Yonelinas, A. (1999). The contribution of recollection and familiarity to recognition and source-memory judgments: A formal dual-process model and an ROC analysis. Journal of Experimental Psychology: Learning, Memory, and Cognition, 25, 1415-1434. doi:10.1037/0278-7393.25.6.1415 
Table 1

Digit span (ability score) and uncorrected proportionate hit, source, and false alarm (FA) rates of four, five, and six-year-olds in the self-referent and other-referent conditions in Experiments 1, 2, and 3.

\section{Other-referent item}

Self-referent item memory

memory

\begin{tabular}{|c|c|c|c|c|c|c|c|c|}
\hline & $\begin{array}{c}\text { Age } \\
\text { group }\end{array}$ & $\begin{array}{l}\text { Digit } \\
\text { Span }\end{array}$ & Hits & Source & FA & Hits & Source & FA \\
\hline \multirow{3}{*}{ Expt. 1} & 4 yrs & - & .76 & - & .23 & .67 & - & .23 \\
\hline & $5 \mathrm{yrs}$ & - & .91 & - & .06 & .85 & - & .06 \\
\hline & $6 \mathrm{yrs}$ & - & .92 & - & .04 & .88 & - & .04 \\
\hline \multirow{3}{*}{ Expt. 2} & 4 yrs & 110.1 & .83 & .73 & .09 & .80 & .67 & .11 \\
\hline & $5 \mathrm{yrs}$ & 116.0 & .91 & .79 & .05 & .86 & .69 & .09 \\
\hline & $6 \mathrm{yrs}$ & 117.4 & .88 & .85 & .01 & .85 & .78 & .01 \\
\hline \multirow{3}{*}{ Expt. 3} & 4 yrs & 111.7 & .75 & .56 & .11 & .67 & .43 & .07 \\
\hline & $5 \mathrm{yrs}$ & 120.2 & .76 & .63 & .02 & .69 & .49 & .02 \\
\hline & $6 \mathrm{yrs}$ & 122.7 & .75 & .61 & .01 & .68 & .48 & .01 \\
\hline
\end{tabular}

Note. FA rate in Experiment 1 is duplicated across self- and other referent items. 

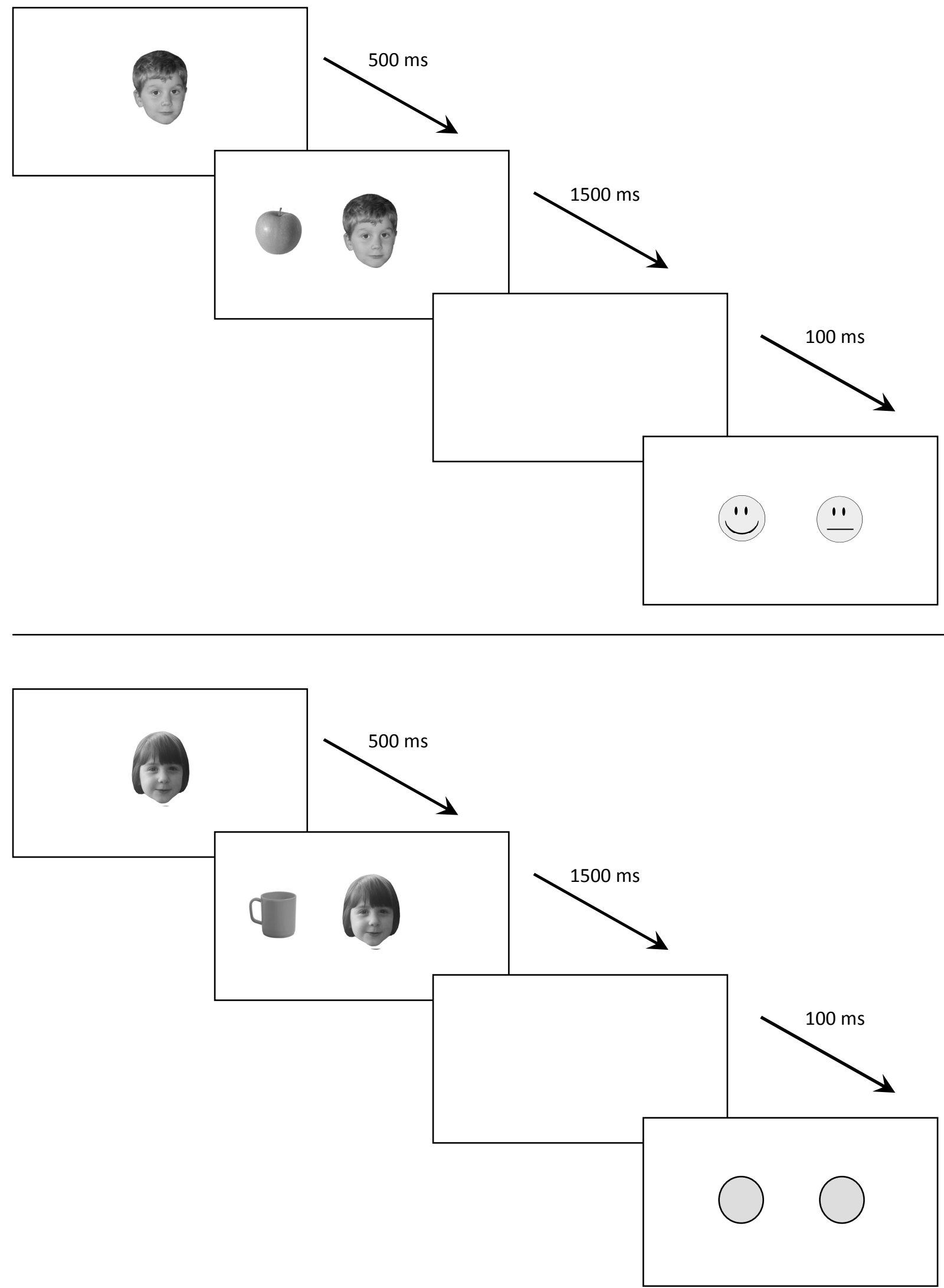

Figure 1. Example trial in the encoding task (Top Panel: Experiments 1 \& 2; Bottom Panel: Experiment 3). 


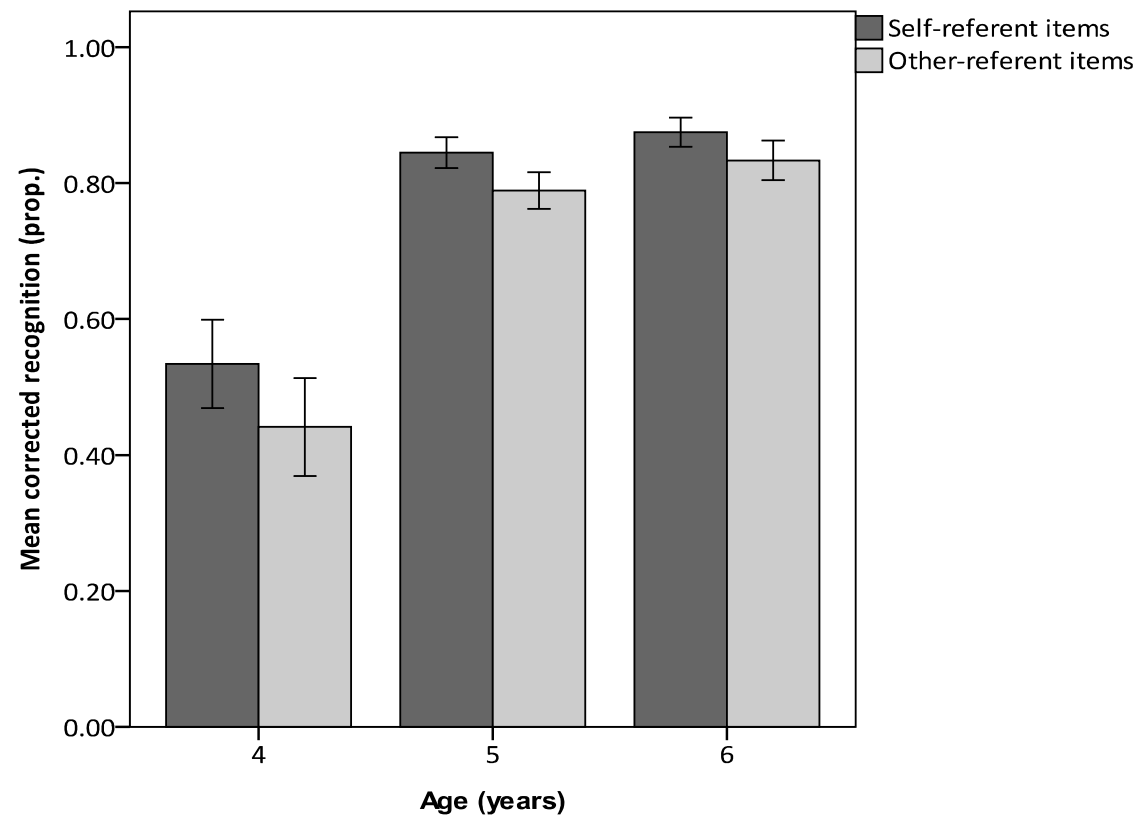

Figure 2. Corrected proportionate recognition scores of 4, 5, and 6 year old children in Experiment 1. (Error bars represent one standard error of the mean.) 


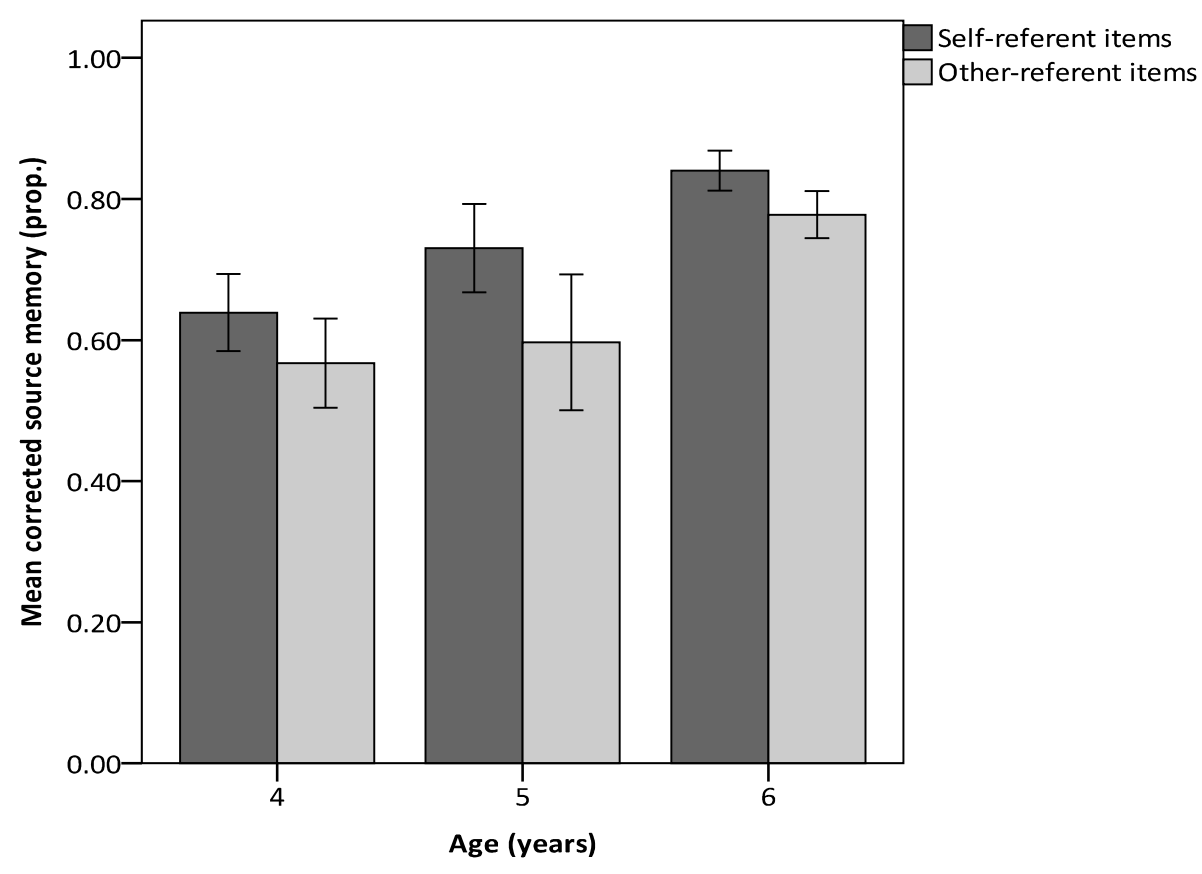

Figure 3. Corrected proportionate source memory scores of 4, 5, and 6 year old children in Experiment 2. (Error bars represent one standard error of the mean.) 


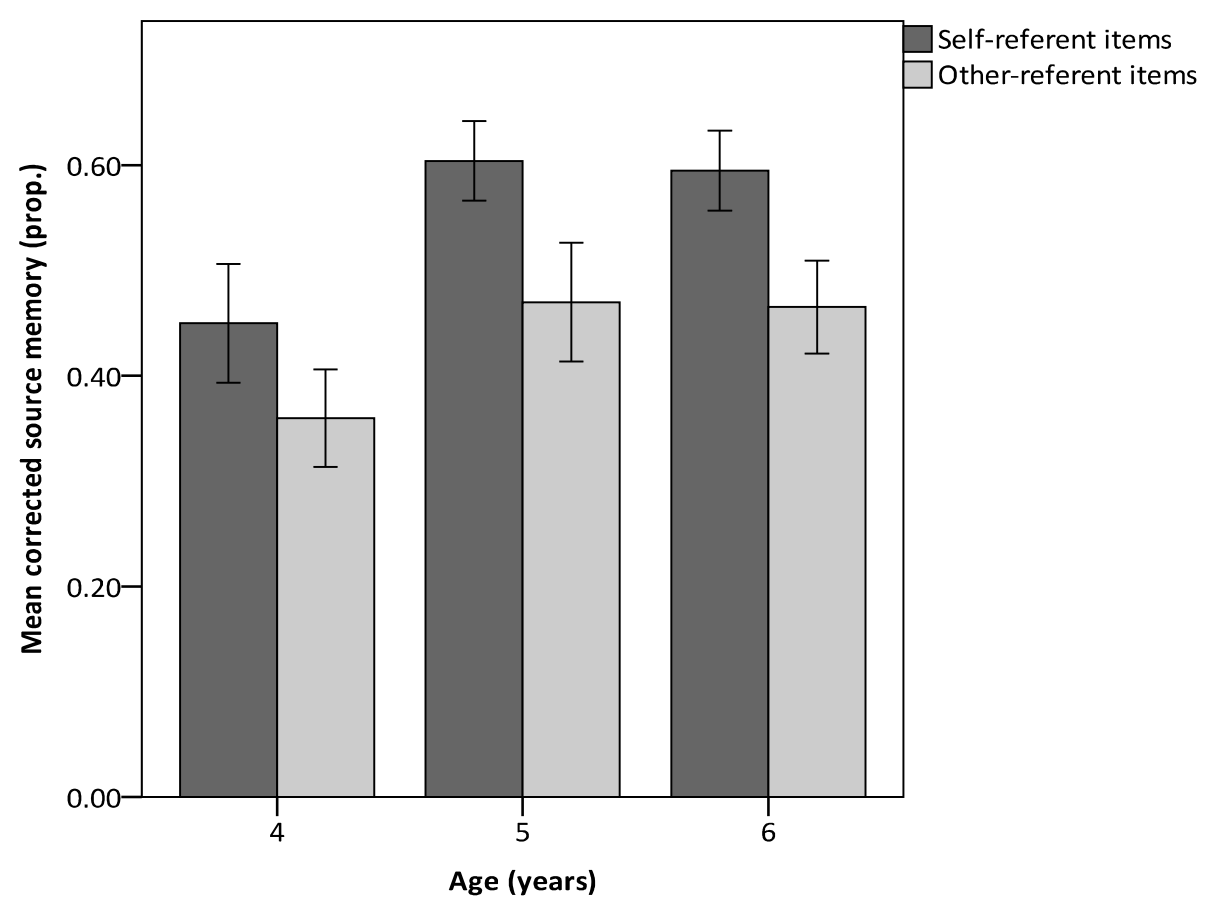

Figure 4. Corrected proportionate source memory scores of 4, 5, and 6 year old children in Experiment 3. (Error bars represent one standard error of the mean.) 


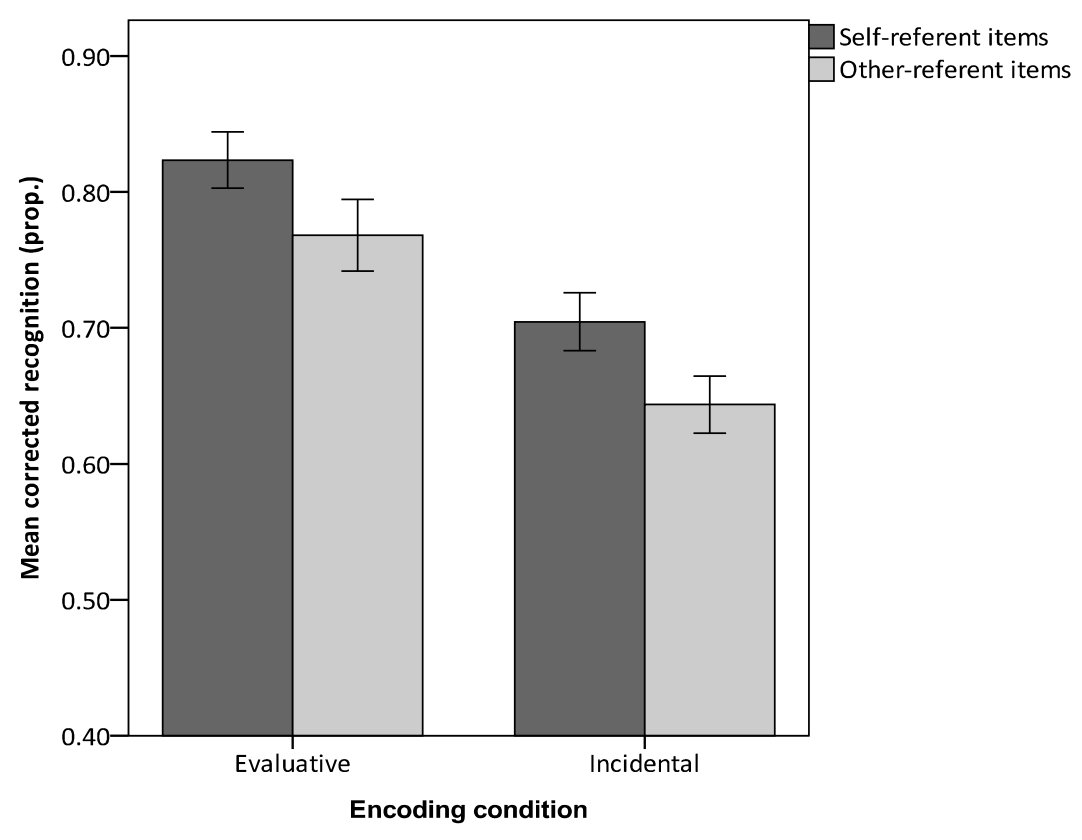

Figure 5. Corrected proportionate recognition scores for self-referent and other-referent items in Experiments 2 and 3, collapsed across age group. (Error bars represent one standard error of the mean.) 